\title{
The Implementation of the Health Impact Assessment (HIA) in Val d'Agri (Italy) and the Direct Involvement of Citizens in Monitoring Activities
}

\author{
A. Demarinis Loiotile, G. de Gennaro, S. Petraccone \\ Department of Biology, University of Bari Aldo Moro, Via Orabona, 4, 70126 Bari; \\ annamaria.demarinis@uniba.it
}

\begin{abstract}
Health Impact Assessment (HIA) is a practical tool, which can be used for evaluating the health impact of a proposed program, project, policy, strategy and initiative in sectors that indirectly affect health and well-being and inform decision-makers of these potential outcomes before the decision is made, supporting the identification of appropriate policy options. The 'Project for the construction of a health impact assessment in the municipalities of Grumento Nova and Viggiano in Val d'Agri', launched by a multidisciplinary research team, proposes the realization of an HIA in Val d'Agri (Basilicata - South of Italy); the interest for its implementation in this area is due to the presence of the largest Italian gas and oil pre-treatment plant, called the "Centro Oli Val d'Agri" (COVA), which performs a first processing of the crude oil extracted from the various wells on the surrounding territory.

In this project the task of the research group of the University of Bari is to monitor conventional and non-conventional pollutants at the high spatial-temporal resolution, performed by standard and innovative methodological approaches and integrated technologies that are able to provide real time information about the emissive situation and the impacts on the territory. In particular, the project involves the activity of odour monitoring both by means of electronic noses and dynamic olfactometry according to UNI EN 13725. The odour impact assessment will also be carried out by involving citizens by means of an experimental methodology for the detection and evaluation of olfactory annoyance.
\end{abstract}

Key words: Health Impact Assessment, odour annoyance, citizen science, odour monitoring, innovative sampling systems, oil extraction.

\section{Introduction}

Health Impact Assessment (HIA) may be defined as 'a methodology which enables the identification, prediction and evaluation of the likely changes in health risk, both positive and negative (single or collective) of a policy programme, plan or development action on a defined population. These changes may be direct and immediate or indirect and delayed [1, 2].

The Health Impact Assessment is intended to incorporate a wide range of health determinants and their potential effects on health and wellbeing [3].

Using qualitative, quantitative and participatory techniques, HIA aims to add value to the decision-making process and produce recommendations that will help decisionmakers and other stakeholders make choices about alternatives and improvements to prevent disease/injury and to actively promote health.
HIA is based on four values that link the HIA to the policy environment in which it is being undertaken [4]:

1. Democracy - allowing people to participate in the development and implementation of policies, programs or projects that may impact on their lives.

2. Equity - HIA assesses the distribution of impacts from a proposal on the whole population, with a particular reference to how the proposal will affect vulnerable people (in terms of age, gender, ethnic background and socio-economic status).

3. Sustainable development - that both short and long term impacts are considered, along with the obvious, and less obvious impacts.

4. Ethical use of evidence - the best available quantitative and qualitative evidence must be identified and used in the assessment. A wide variety of evidence should be collected using the best possible methods. 
The HIA typically consists of a series of steps that are intended to provide a structural framework, around which the assessment will be conducted:

- Screening (identifying plans, projects or policies for which an HIA would be useful),

- Scoping (identifying which health effects to consider),

- Assessing risks and benefits (identifying which people may be affected and how they may be affected),

- Developing recommendations (suggesting changes to proposals to promote positive health effects or to minimize adverse health effects),

- Reporting (presenting the results to decision-makers), and

- Monitoring and evaluating (determining the effect of the HIA on the decision).

The HIA is strongly reliant on inter-sectorial collaboration, both across various sectors, but also across policy-making and practice [5].

The paper focuses on the management and realization of the Project for the construction of a health impact assessment in the municipalities of Grumento Nova and Viggiano in Val d'Agri.

\section{The Project's activities}

The Project for the construction of a health impact assessment in the municipalities of Grumento Nova and Viggiano in Val d'Agri was launched by a multidisciplinary research team: it has been defined and developed by the Environmental Epidemiology and disease registries Unity - Institute of Clinical Physiology, National Research Council (CNR), in collaboration with researchers from the Department of Biology of the University of Bari, the Institute for Atmospheric Sciences and Climate of the National Research Council, the Institute for the Study of Ecosystems of CNR, the Consorzio Mario Negri Sud, and the Department of Epidemiology of the Lazio Region.

The project proposes the realization of an HIA in Val d'Agri (Basilicata - Italy); the interest for its realization in this area is due to the presence of the largest Italian gas and oil pre-treatment plant, called "Centro Oli Val d'Agri" (COVA), which performs a first processing of the crude oil extracted from the various wells on the surrounding territory. It is located in the industrial area of Viggiano (PZ), a small village in the South of Italy and covers an area of 171 $700 \mathrm{~m}^{2}$ [6] (Figure 1).

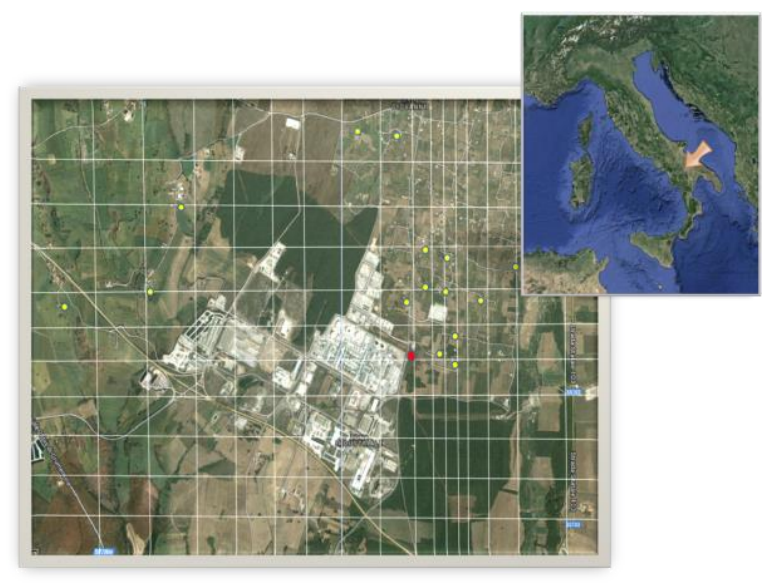

Fig. 1. The "Centro Oli Val d'Agri" (COVA) and its position in south of Italy.

Areas characterized by intense drilling activities usually have wells close enough to each other so that the risk cannot be modeled by considering a simple point source, but rather it should be considered as different risk point sources. The operation of oil refineries and petrochemical plants is associated with the emission of Volatile Organic Compounds (VOC), mainly deriving from production processes, from storage tanks, gas pipelines and exhausted areas [7].

Since the extraction of oil is carried out in populated areas, human beings and animals that live in these areas become organic supplements of chemicals released by this type of industrial activity $[8,9]$.

An epidemiological approach capable of analyzing the effects on human health in the vicinity of areas of petroleum extraction and processing is necessary in order to identify the potential risks on human health in these areas.

In this project the task of the research group of the University of Bari is to monitor conventional and non-conventional pollutants at the high spatial-temporal resolution, performed by standard and innovative methodological approaches and integrated technologies that are able to provide real time information about the emissive situation and the impacts on the territory.

The research group will conduct the following activities:

- determination of VOC by means of passive samplers and a network of PID sensors in order to achieve a smart network which allows us to obtain time profiles of these compounds and a mapping of the territory;

- determination of VOC by means of personal dosimeters; 
- breath sampling of volunteers and determination of VOC for the early diagnosis and screening of chronic diseases and cancer;

- monitoring of $\mathrm{PM}_{10}$ and $\mathrm{PM}_{2.5}$ fractions and determination of Polycyclic Aromatic Hydrocarbon (PAH) including benzo(a)pyrene, which is listed as a Group 1 carcinogen by the International Agency for Research on Cancer (IARC);

- odour monitoring both by means of electronic noses and dynamic olfactometry according to UNI EN 13725. The odour impact assessment will also be carried out by involving citizens by means of an experimental methodology for the detection and evaluation of olfactory annoyance.

\section{The experimental methodology for the detection and evaluation of olfactory annoyance}

Odour emission is considered as one of the most important causes of population complaints and its evaluation represents a matter characterized by great complexity, due principally to the strict association of odour pollution to human perception [10]. In fact, the need to establish a causal relation between odour events (often characterized by a brief duration) and odour sources is often problematic. On the other hand, population living in the surroundings of odour sources denounces the occurrence of odour events to the local authorities (municipalities, public security, environmental agencies, etc.), that are often overwhelmed by continuous complaints, not easily manageable. Moreover, another aspect to take into account is the evaluation of the reliability of population complaints and how it is possible to make objective these warnings.

The new proposed experimental approach is able to integrate automatic remote systems in order to record the olfactory perception of human receptors and to collect odour samples in real time.

The system consists of a telephonic system that systematizes the population complaints and of automatic sampling systems, remotely activable, able to collect air sample in real time, at the moment of the significant odour events. The approach allows to:

- systematize and digitalize telephone complaints;

- display the reports on real-time map;

- activate remotely sampling system in real time.

Each citizen (called receptor) will be georeferenced on the map and coded inside the system database. Using a telephone switchboard, the receptor will communicate the odour perception and also its intensity (via the telephone keypad), choosing among three level of intensity, visualized with different colors.

The phone calls will be recorded and displayed on the map in real time on a website, accessible from stakeholders. The graphical interface allows to interact with database to obtain information regarding date, time and number of calls in a synoptic visualization or in a graphical one.

The setting of specific routine, based on the number of calls for index of intensity in a period of time, allows to activate remotely sampling systems, depression pumps, located in a chosen representative site. They collect air samples in real time which will be measured by means of dynamic olfactometry, according to the technical law EN 13725/2003.

The information about the pump activation is immediately sent to the technical operators through telephone messages in order to pick up the sample and prepare the olfactometric measurement within 30 hours.

Figure 2 shows the system architecture through a schematic diagram:

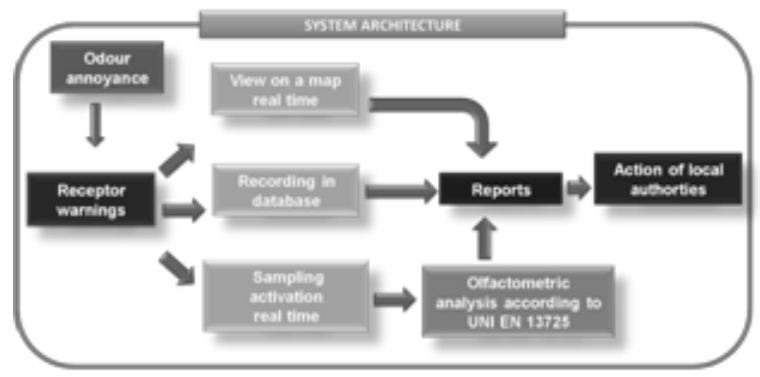

Fig. 2. Schematic diagram related to the system architecture.

This activity will be carried out in Val d'Agri for 7 months starting in December 2016. The direct involvement of citizens in this activity will allow to scientifically validate the complaints of citizens.

Crossing the citizens warnings with weather data and air quality data, the emission phenomenon may be better studied and the most impactful sources identified.

\section{Conclusions}

The lack of an overall framework including the various sources of pollutants emissions, as well as the presence of critical events related to the management of processes and fugitive emissions of the plant suggest the opportunity to deepen the study of the territory and the 
population potentially exposed to the pollution sources. The small territorial and population size, together with weather-climatic characteristics and the nature of the critical events, indicate how suitable would be an integrated study model based on the reconstruction of relapse patterns, the spread of pollutants and the assessment of possible adverse effects on the human health at micro geographical scale, including the participation of all stakeholders.

Moreover, the direct involvement of citizens in the monitoring activities allows to identify this project as a good example of 'citizen science project'. Collaborations between scientists and volunteers have the potential to broaden the scope of research and enhance the ability to collect scientific data [11].

\section{Acknowledgements}

The authors would like to acknowledge the support of the Institute of Clinical Physiology, National Research Council (CNR-IFC), the Municipalities of Viggiano and Grumento Nova.

\section{References}

[1] D. Morgan, (ed.), Health and Environmental Impact Assessment. Earthscan Publications Ltd (1998), London, UK

[2] J. Kemm, Health Impact Assessment: a tool for Healthy Public Policy, Oxford Journals - Medicine \& Health - Health Promotion International, Volume 16, Issue 1 - Pp. 79-85 (2001).

[3] L.C. Mccallum, K. Souweine, M. Mcdaniel, B. Koppe, C. Mcfarland, K.Butler, and C. A. Ollson, Health impact assessment of an oil drilling project in California, International Journal of Occupational Medicine and Environmental Health 2016;29(2),

http://dx.doi.org/10.13075/ijomeh.1896.00551

[4] http://www.who.int/hia/about/why/en/

[5] European Policy Health Impact Assessment - A Guide, ISBN $1874038 \quad 75 \quad 9, \quad 2004$ http://ec.europa.eu/health/ph_projects/2001/monit oring/fp_monitoring_2001_a6_frep_11_en.pdf

[6] M. Faruolo, I. Coviello, C. Filizzola, T. Lacava, N. Pergola, and V. Tramutoli, A satellite-based analysis of the Val d'Agri (South of Italy) Oil Center gas flaring emissions", Nat. Hazards Earth Syst. Sci. Discuss., 2 (2014), 4101-4133.

[7] P.D. Kalabokas, J. Hatzaianestis, J.G. Bartzis, P. Papagiannakopoulos, Atmospheric concentrations of saturated and aromatic hydrocarbons around a Greek oil refinery, Atmos. Environ. 35 (2001) 2545 -2555.

[8] M. Bamberger, R.E. Oswald, Impacts of gas drilling on human and animal health, New Solut. 22(1):51-77(2012). doi:10.2190/NS.22.1.e.
[9] M. Bamberger, R.E. Oswald, Long-term impacts of unconventional drilling operations on human and animal health, $J$ Environ Sci Health A Tox Hazard Subst Environ Eng., 50(5):447-59 (2015). doi:10.1080/10934529.2015.992655.

[10] M. Brattoli, G. de Gennaro, V. de Pinto, A. Demarinis Loiotile, S. Lovascio, M. Penza, Odour Detection Methods: Olfactometry and Chemical Sensors. Sensors (2011), 11, 5290-5322

[11] J. P. Cohn, Citizen Science: Can Volunteers Do Real Research? BioScience 58 (3): 192-197 (2008). 